Conf- $9505+05--2$ GA-A22063

\title{
CURRENT PROFILE EVOLUTION DURING FAST WAVE CURRENT DRIVE ON THE DIII-D TOKAMAK
}

\author{
by \\ C.C. PETTY, C.B. FOREST, F.W. BAITY, \\ S.C. CHIU, J.S. deGRASSIE, R.J. GROEBNER, \\ Y.R. LIN-LIU, T.C. LUCE, R.I. PINSKER, \\ M. PORKOLAB, R. PRATER, and B.W. RICE
}

JUNE 1995 


\section{DISCLAIMER}

This report was prepared as an account of work sponsored by an agency of the United States Government. Neither the United States Government nor any agency thereof, nor any of their employees, make any warranty, express or implied, or assumes any legal liability or responsibility for the accuracy, completeness, or usefulness of any information, apparatus, product, or process disclosed, or represents that its use would not infringe privately owned rights. Reference herein to any specific commercial product, process, or service by trade name, trademark, manufacturer, or otherwise does not necessarily constitute or imply its endorsement, recommendation, or favoring by the United States Government or any agency thereof. The views and opinions of authors expressed herein do not necessarily state or reflect those of the United States Government or any agency thereof. 


\section{DISCLAIMER}

Portions of this document may be illegible in electronic image products. Images are produced from the best available original document. 


\section{CURRENT PROFILE EVOLUTION DURING FAST WAVE CURRENT DRIVE ON THE DIII-D TOKAMAK}

by

C.C. PETTY, C.B. FOREST, F.W. BAITY,* S.C. CHIU, J.S. deGRASSIE, R.J. GROEBNER, Y.R. LIN-LIU, T.C. LUCE, R.I. PINSKER, M. PORKOLAB, ${ }^{\dagger}$ R. PRATER, and B.W. RICE $\ddagger$

This is a preprint of a paper presented at the 11th Topical Conference on Radio Frequency Power in Plasmas, May 17-19, 1995, Palm Springs, California, and to be printed in the Proceedings.

Work supported by U.S. Department of Energy Contracts DE-AC03-89ER51114, DE-AC05-840R21400, and $W-7405-E N G-48$

* Oak Ridge National Laboratory

† Massachusetts Institute of Technology

¥Lawrence Livermore National Laboratory

GENERAL ATOMICS PROJECT 3466

JUNE 1995 


\title{
Current Profile Evolution During Fast Wave Wave Current Drive on the DIII-D Tokamak
}

\author{
C.C. Petty, C.B. Forest, F.W. Baity, ${ }^{*}$ S.C. Chiu, J.S. deGrassie, \\ R.J. Groebner, Y.-R. Lin-Liu, T.C. Luce, R.I. Pinsker, \\ M. Porkolab, ${ }^{\dagger}$ R. Prater, and B.W. Rice ${ }^{\ddagger}$ \\ General Atomics, San Diego, California 92186 \\ * Oak Ridge National Laboratory, Oak Ridge, Tennessee 37831 \\ ${ }^{\dagger}$ Massachusetts Institute of Technology, Cambridge, Massachusetts 02139 \\ ${ }^{\ddagger}$ Lawrence Livermore National Laboratory, Livermore, California 94551
}

\begin{abstract}
The effect of co and counter fast wave current drive (FWCD) on the plasma current profile has been measured for neutral beam heated plasmas with reversed magnetic shear on the DIII-D tokamak. Although the response of the loop voltage profile was consistent with the application of co and counter FWCD, little difference was observed between the current profiles for the opposite directions of FWCD. The evolution of the current profile was successfully modeled using the ONETWO transport code. The simulation showed that the small difference between the current profiles for co and counter FWCD was mainly due to an offsetting change in the ohmic current profile. In addition, the time scale for the loop voltage to reach equilibrium (i.e., flatten) was found to be much longer than the FWCD pulse, which limited the ability of the current profile to fully respond to co or counter FWCD.
\end{abstract}

\section{INTRODUCTION}

Advanced tokamak scenarios, such as operating with reversed magnetic shear in the plasma core, require control of the plasma current profile to improve the confinement and stability properties of the plasma. Recent experiments on the DIII-D tokamak have applied up to 1.6 MW of fast wave current drive (FWCD) to reversed shear L-mode discharges to investigate the effect on the current profile. The reversed magnetic shear was formed by strong auxiliary heating starting early in the plasma current ramp up using neutral beam injection (NBI), which created a hot target plasma suitable for FWCD [1]. 
The temporal evolution of the poloidal flux profile was measured in these sawtooth-free discharges which allowed the plasma current and loop voltage profiles to be determined. These experiments found that the measured current profile was broader for counter FWCD than for co FWCD; however, the difference was surprisingly small considering that measurements of the loop voltage profile showed that the co FWCD was driving all of the plasma current near the plasma center [2]. In order to understand these results, the evolution of the plasma current profile has been simulated using the ONETWO code.

\section{NBI DISCHARGES WITHOUT FWCD}

In order to benchmark the ONETwO simulation of the current profile evolution against experimental measurements, a case of NBI heating without FWCD was studied for a reversed shear discharge. The ONETWO code models the relaxation of the plasma loop voltage from an initial condition to a flat spatial profile according to Faraday's law. The loop voltage profile at the start of the ONETWO simulation was determined using the equation

$$
V_{\mathrm{L}}=2 \pi R \eta_{\text {neo }}\left(J_{\text {tot }}-J_{\text {bs }}-J_{\text {cd }}\right) \text {, }
$$

where $R$ is the major radius, $\eta_{\text {neo }}$ is the neoclassical resistivity, $J_{\text {tot }}$ is the experimentally measured plasma current density, $J_{\mathrm{bs}}$ is the calculated bootstrap current density, and $J_{\mathrm{cd}}$ is the externally driven current density. A 16-channel motional Stark effect diagnostic was used in the determination of the plasma current density profile [3]. A Monte Carlo code was used to model the neutral beam current drive (NBCD). The time history of the electron temperature, ion temperature, electron density, $Z_{\text {eff }}$, and toroidal rotation velocity were also included in the modeling.

The ONETwO benchmark simulation was found to be in good agreement with experiment. The temporal evolution of the simulated and measured internal inductance, surface loop voltage, and central safety factor agree well with the measured values. A comparison of the predicted loop voltage profile with the experimentally measured profile, a more stringent test of the accuracy of the simulation, is shown in Fig. 1. The good agreement between the simulation and experiment shows that the ONETWO code correctly models the relaxation of the loop voltage profile; this is strong evidence that neoclassical resistivity, which governs the time scale of this relaxation process as well as the magnitude of the loop voltage, is the correct plasma resistivity model.

\section{COMPARISON OF CO AND COUNTER FWCD}

Experiments to observe the effect of co and counter FWCD on the evolution of the plasma current profile found that while co FWCD did peak the current profile more than counter, the difference was small. This can 


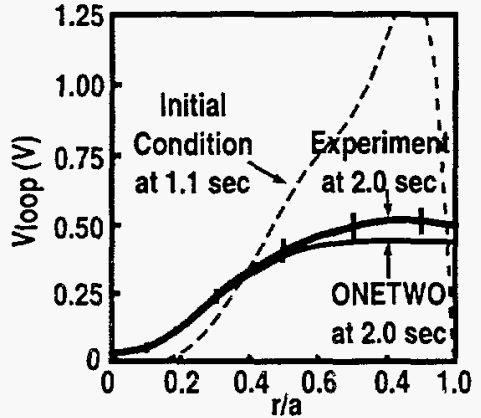

FIGURE 1. Comparison of loop voltage profile from ONETWO simulation with experiment $\left(I_{p}\right.$ $=1.4 \mathrm{MA}, \mathrm{B}_{\mathrm{T}}=2.1 \mathrm{~T}, \overline{\mathrm{n}}=2.1$ $\times 10^{19} \mathrm{~m}^{-3}, P_{\text {beam }}=4.4 \mathrm{MW}$ ). be seen in Fig. 2, where the measured values of internal inductance, surface loop voltage, and central safety factor are shown as a function of time for two discharges: one with 1.4 MW of co FWCD and the other with 1.0 MW of counter FWCD. The plasma conditions were nearly identical for the co and counter cases; the calculated NBCD and bootstrap currents were also the same for these two discharges.

The experimentally determined difference in the non-inductive current drive between the plasmas with co antenna phasing and counter antenna phasing was $230 \mathrm{kA}$ [2], nearly all of which was inside a radius of $r / a=0.4$. Therefore the change in the non-inductive current density near the plasma center for co and counter FWCD was comparable to the total current density. With such a significant change, it seemed surprising that there was not a larger difference in the current profile between the co and counter current drive discharges.

Modeling the evolution of the plasma current profile using ONETWO provided insight. The CURRAY ray tracing code was used to calculate the theoretical FWCD [4]. The temporal evolution of the internal inductance, surface loop voltage, and central safety factor from the ONETWO simulations are shown in Fig. 3. The simulated quantities closely predict both the magnitudes of the experimental quantities as well as the nearness of the co FWCD to the counter FWCD results.

These ONETWO simulations showed that the mitigating effect of the large ohmic current (which was about eight times the current driven by fast waves) was the main reason the plasma current profile did not change much between co and counter FWCD. Since the total plasma current was held fixed in these experiments by the ohmic transformer, the smaller amount of non-inductive current drive for the counter FWCD case (compared to the co case) was exactly offset by a greater amount of ohmic current produced by a higher loop voltage. Since the
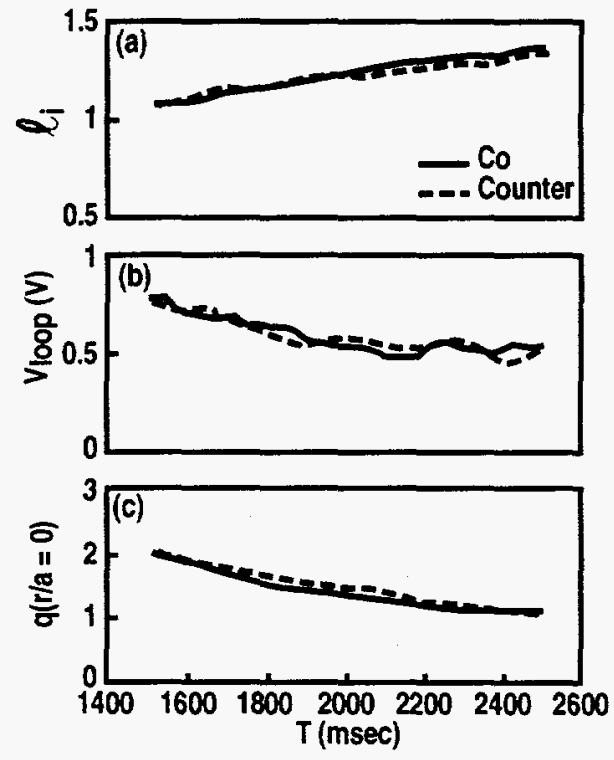

FIGURE 2. Comparison of co and counter FWCD discharges with NBI heating: (a) measured internal inductance, (b) measured surface loop voltage, and (c) measured central safety factor $\left(I_{p}\right.$ $=1.4 \mathrm{MA}, \mathrm{B}_{\mathrm{T}}=2.1 \mathrm{~T}, \overline{\mathrm{n}}=1.9$ $\times 10^{19} \mathrm{~m}^{-3}, P_{\text {beam }}=3.5 \mathrm{MW}$ ). 

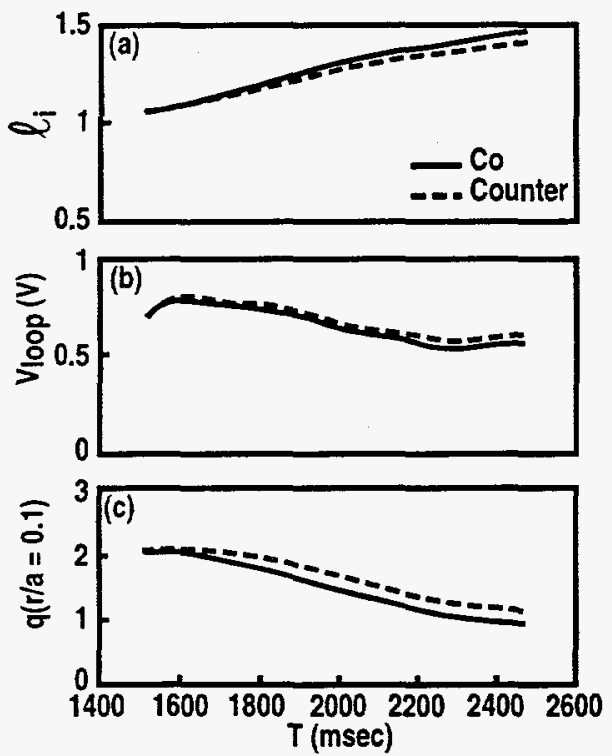

FIGURE 3. Comparison of $\mathrm{CO}$ and counter FWCD from ONETWO simulations of the discharges shown in Fig. 2: (a) simulated internal inductance, (b) simulated surface loop voltage, and (c) simulated central safety factor. neoclassical resistivity increases rapidly with minor radius, the ohmic current profile was peaked on axis and thus was similar to the FWCD profile. Therefore replacing co FWCD with an equal amount of ohmic current plus counter FWCD left the plasma current profile relatively unchanged. In order to create a larger difference in the current profiles between co and counter FWCD, the level of ohmic current needs to be reduced relative to the amount of FWCD and/or the ohmic current profile needs to be broadened relative to the FWCD profile (by broadening the electron temperature profile). Another reason for the small difference in the current profiles for co and counter FWCD was that the time scale for the loop voltage profile to flatten was much longer than the FWCD pulse. For example, the ONETWO simulation shown in Fig. 3 found that the current profile reached a steady state $9 \mathrm{sec}$ after the start of FWCD, whereas the actual fast wave pulse was only $2 \mathrm{sec}$ long. Therefore the current profile did not have sufficient time to fully respond to either co or counter FWCD.

\section{ACKNOWLEDGMENT}

This is a report of work supported by U.S. DOE Contracts DE-AC0389ER51114, DE-AC05-84OR21400, and W-7405-ENG-48.

\section{REFERENCES}

[1] C.C. Petty et al., Phys. Rev. Lett. 69, 289 (1992).

[2] C.B. Forest et al., "Experimentally Determined Profiles of Fast Wave Current Drive in DIII-D," this conference.

[3] D. Wròblewski and L.L. Lao, Rev. Sci. Instrum. 63, 5140 (1992).

[4] T.K. Mau et al., in Radiofrequency Heating and Current Drive of Fusion Devices 1992 (Proc. 19th Euro. Conf. Brussels) Vol. 16E, p. 181. 